\title{
MORPHOMETRIC STUDY OF SEGMENTS OF HUMERUS IN
} POPULATION OF BIHAR

\author{
Sanjeev Kumar Sinha ${ }^{1}$, Sanjay Kumar ${ }^{* 1}$, Margaret Roshni Dhan ${ }^{1}$, Vinod kumar ${ }^{2}$. \\ ${ }^{{ }_{1}}$ Assistant Professor, Department of Anatomy, Narayan Medical College, Sasaram, Bihar, India. \\ ${ }^{2}$ Professor, Department of Anatomy, Narayan Medical College, Sasaram, Bihar, India.
}

\section{ABSTRACT}

Background: The humerus has upper end, lower end and a cylindrical shaft. In absence of cranium, pelvis and long bones of lower limbs, estimation of living stature can be assessed by long bones such as humerus, radius and ulna. We can also find out the total length of humerus by its fragments. Morphometry of distal end of humerus is also important for determination of sex.

Materials and methods: The present study was conducted on 60 dry humerus of unknown age and sex collected from department of anatomy of Narayan Medical College and also from other medical colleges of Bihar. 6 different parameters were taken from this study.

Result: Total 60 humerus were included in this study, out of which 30 were right and 30 were left. Mean maximum length of humerus were $307.58 \pm 8.46 \mathrm{~mm}$. Mean transverse and vertical diameter of head of humerus were $39.06 \pm 1.26 \mathrm{~mm}$ and $41.43 \pm 1.02 \mathrm{~mm}$ respectively. Mean distance between proximal \& distal edge of olecranon fossa were $18.39 \pm 0.93 \mathrm{~mm}$. Mean distance between distal edge of olecranon fossa \& trochlea $15.00 \pm 0.82 \mathrm{~mm}$. Mean distance between proximal edge of olecranon fossa \& distal edge of trochlea were $33.39 \pm 1.32 \mathrm{~mm}$. Conclusion: The knowledge of Morphometric segments of Humerus is important to establish the length of humerus, stature, age and sex of individual and it is important for anatomists, forensic experts, archeologists. It is also helpful for orthopaedic surgeons in proximal and distal fracture of humerus and its reconstructive surgery for various implants.

KEY WORDS: Humerus segment, Morphometry, Anthropometry.

Corresponding Author: Dr. Sanjay Kumar, Assistant Professor, Department of Anatomy, Narayan Medical College, Sasaram, Bihar, India. E-Mail: drsanjayatdmch@gmail.com

Access this Article online

Quick Response code

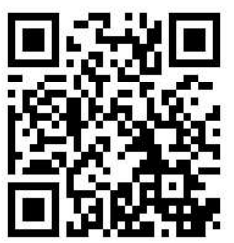

DOI: $10.16965 /$ ijar.2019.342

\begin{tabular}{|c|c|c|}
\hline \multicolumn{3}{|c|}{ Journal Information } \\
\hline $\begin{array}{c}\text { International Journa } \\
\left.\begin{array}{c}\text { ICV for } 2016 \\
\mathbf{9 0 . 3 0}\end{array}\right) \begin{array}{r}\text { ISSN (E) 2321-4 } \\
\text { https://ww }\end{array}\end{array}$ & $\begin{array}{l}\text { Anatomy and Res } \\
\text { ISSN (P) 2321-8967 } \\
\text { hr.org/ijar.htm }\end{array}$ & ch \\
\hline \multicolumn{3}{|c|}{ Article Information } \\
\hline Received: 13 Nov 2019 & Accepted: 12 Dec & \\
\hline Peer Review: 13 Nov 2019 & Published (0): 05 & 2020 \\
\hline Revised: None & Published (P): 05 & 2020 \\
\hline
\end{tabular}

\section{INTRODUCTION}

The humerus is the longest and strongest bone of upper extremity. It has expanded upper end, lower end and a cylindrical shaft. Upper end consist of head, neck, greater and lesser tubercle and intertubercular sulcus. Lower end consist of capitulum, trochlea, radial fossa, coronoid fossa, olecranon fossa, medial and lateral epicondyles. Intact humerus and its segments is very important for anatomists and forensic experts to investigate the identity of a skeleton. In anthropology and forensic science, morphometric analysis is carried out on remains of the long bones of the individual in absence of cranium and pelvis [1-3).

In long bones, femur and tibia collectively remains the best for assessment of living stature of the individual $[4,5]$. However in absence of long bones of lower limb, estimation of living stature can also be assessed by the long bones of upper limb such as humerus, radius and ulna $[6,7]$. When the whole length of long bones are not available, but only segment of bones is available, some methods can be 
employed for usefulness of fragments of humerus [1]. We can find out the total humerus length by fragments of humerus for estimation of sex [8]. Morphometry of distal end of humerus is also important for determination of sex [9]. Mullers was the first scientist who measured the five segments of humerus by using margin of articular surfaces and key point of muscle attachment [1].

It is also important for orthopaedics surgeons in proximal and distal fracture of humerus. The measurememt of various segments of humerus is very important to provide data for various impalnts in reconstruction of various humerus fracture. The present study is conducted for morphometric study of segments of humerus.

\section{MATERIALS AND METHODS}

The present study was conducted on 60 dry humerus of unknown age and sex obtained from department of Anatomy, Narayan Medical College, Sasaram and also from other medical colleges of Bihar. Humerus were complete in all respects. Incomplete or damaged bones were excluded from the study.

Measurement of 6 different parameters were taken from this study:

1. Maximum length of humerus- it is the distance between highest point of head of humerus and most distal point of trochlea.

2. Maximum transverse diameter of head- it is the straight distance between the most lateral points on the articular surface of head.

3. Maximum vertical diameter of head-it is the straight distance between hightest and lowest points on articular surface

4. Distance between proximal and distal edge of olecranon fossa

5. Distance between distal edge of olecranon fossa and trochlea

6. Distance between proximal edge of olecranon fossa and distal edge of trochlea.

\section{RESULTS}

Total 60 humerus were included in this study, out of which 30 were right and 30 were left. Maximum length of right and left humerus were $310.96 \pm 7.08 \mathrm{~mm}$ and $304.20 \pm 8.49 \mathrm{~mm}$ respectively while the total maximum length of humerus were $307.58 \pm 8.46$. Mean transverse diameter of head of humerus were $39.01 \pm 1.53$ $\mathrm{mm}$ on right side, $39.12 \pm 0.93 \mathrm{~mm}$ on left side and $39.06 \pm 1.26 \mathrm{~mm}$ of total humerus. The mean vertical diameter of head of humerus were $41.55 \pm 1.12 \mathrm{~mm}$ on right side, $41.30 \pm 0.90 \mathrm{~mm}$ on left side and $41.43 \pm 1.02 \mathrm{~mm}$ of total humerus. Mean distance between proximal \& distal edge of olecranon fossa were $18.36 \pm 1.08$ $\mathrm{mm}$ on right side, $18.41 \pm 0.77 \mathrm{~mm}$ on left side and $18.39 \pm 0.93 \mathrm{~mm}$ of total humerus. Mean distance between distal edge of olecranon fossa \& trochlea $15.10 \pm 0.82 \mathrm{~mm}$ on right side, $14.90 \pm 0.81 \mathrm{~mm}$ on left side and $15.00 \pm 0.82 \mathrm{~mm}$ of total humerus. Mean distance between proximal edge of olecranon fossa \& distal edge of trochlea $33.47 \pm 1.41 \mathrm{~mm}$ on right side, $33.31 \pm 1.24 \mathrm{~mm}$ on left side and $33.39 \pm 1.32$ of total humerus.

Fig. 1: Different measurement of Humerus.

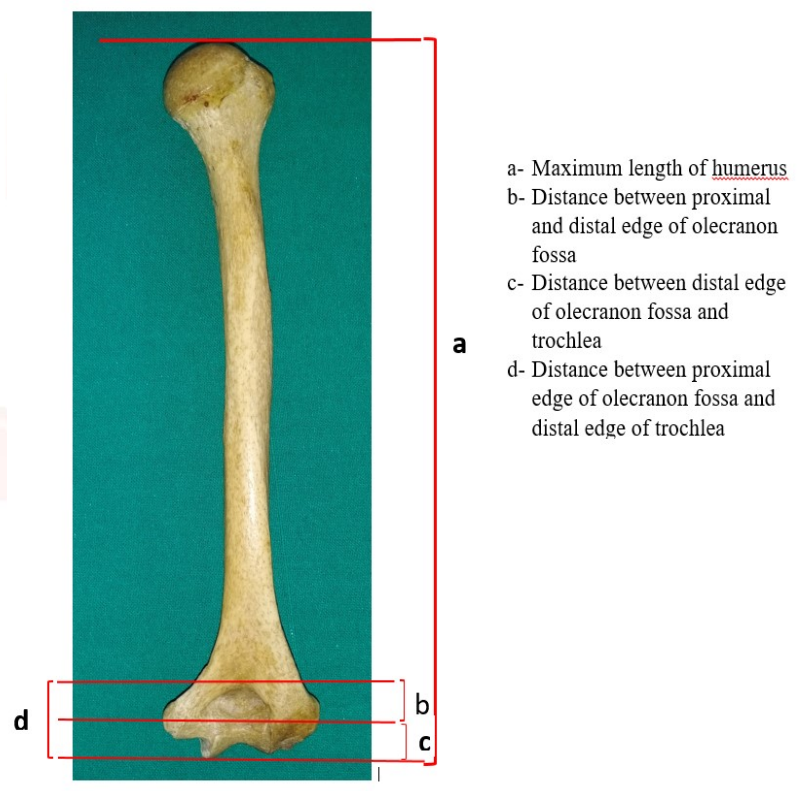

Fig.2: Measurement of Maximum transverse \& vertical diameter of head of Humerus.
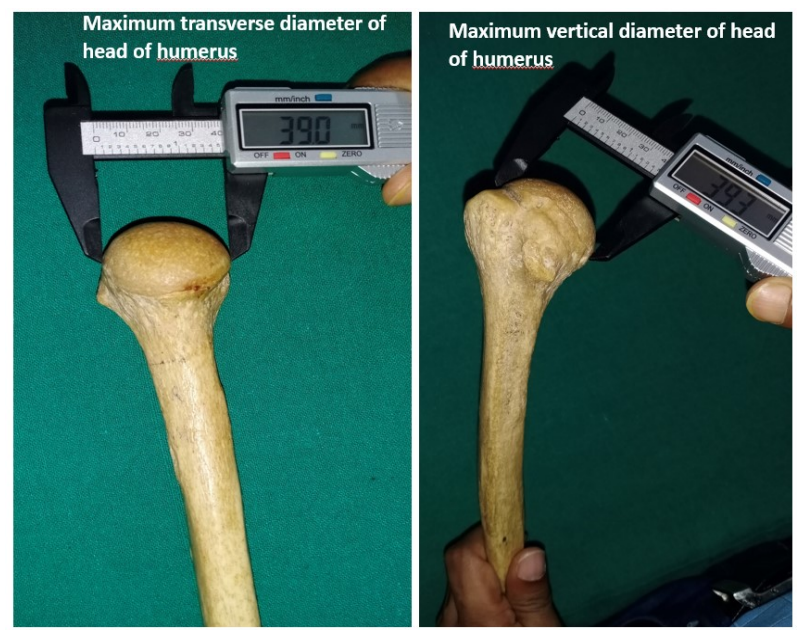
Fig.3: Measurement of olacranon fossa \& trochlea.
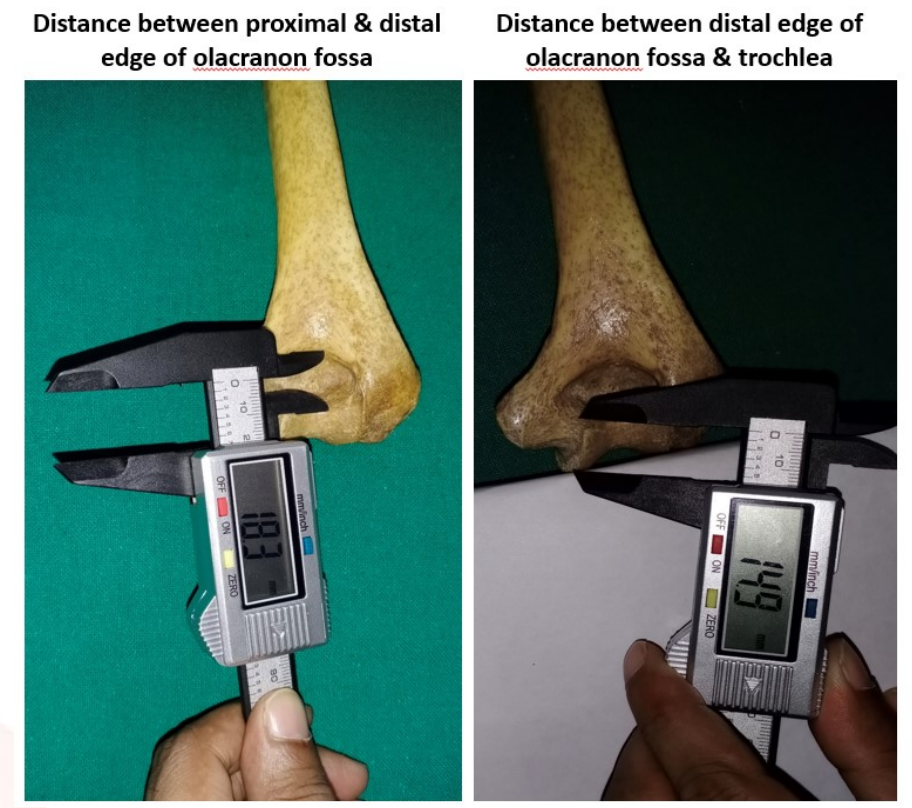

Table. 1: Parameters of Humerus.

\begin{tabular}{|c|l|c|c|c|}
\hline S.No. & \multicolumn{1}{|c|}{ Parameters $(\mathrm{mm})$} & Right & Left & Total \\
\hline $\mathbf{1}$ & Maximum length of Humerus & $310.96 \pm 7.08$ & $304.20 \pm 8.49$ & $307.58 \pm 8.46$ \\
\hline $\mathbf{2}$ & $\begin{array}{l}\text { Mean transverse diameter of Head of } \\
\text { Humerus }\end{array}$ & $39.01 \pm 1.53$ & $39.12 \pm 0.93$ & $39.06 \pm 1.26$ \\
\hline $\mathbf{3}$ & $\begin{array}{l}\text { Mean vertical diameter of Head of } \\
\text { Humerus }\end{array}$ & $41.55 \pm 1.12$ & $41.30 \pm 0.90$ & $41.43 \pm 1.02$ \\
\hline $\mathbf{4}$ & $\begin{array}{l}\text { Mean distance between proximal \& } \\
\text { distal edge of olecranon fossa }\end{array}$ & $18.36 \pm 1.08$ & $18.41 \pm 0.77$ & $18.39 \pm 0.93$ \\
\hline $\mathbf{5}$ & $\begin{array}{l}\text { Mean distance between distal edge of } \\
\text { olecranon fossa \& trochlea }\end{array}$ & $15.10 \pm 0.82$ & $14.90 \pm 0.81$ & $15.00 \pm 0.82$ \\
\hline $\mathbf{6}$ & $\begin{array}{l}\text { Mean distance between proximal } \\
\text { edge of olecranon fossa \& distal edge } \\
\text { of trochlea }\end{array}$ & $33.47 \pm 1.41$ & $33.31 \pm 1.24$ & $33.39 \pm 1.32$ \\
\hline
\end{tabular}

\section{DISCUSSION}

Table 2: Showing comparison of maximum length of Humerus.

\begin{tabular}{|l|c|c|c|}
\hline \multicolumn{1}{|c|}{ Authors } & Year & Right & Left \\
\hline Akman et al [11] & 2006 & $307.1+20.6$ & $304 \pm 18.9$ \\
\hline Somesh M.S et al [15] & 2011 & $309.6+20.6$ & $299.6+22.5$ \\
\hline Present study & 2019 & $310.96 \pm 7.08$ & $304.20 \pm 8.49$ \\
\hline
\end{tabular}

Table 3: Showing Comparison of transverse diameter of head of Humerus.

\begin{tabular}{|c|c|c|c|}
\hline Authors & Year & Right & Left \\
\hline Pranoti et al [10] & 2017 & $38.85 \pm 5.09$ & $38.18, \pm 4.79$ \\
\hline Present study & 2019 & $39.01 \pm 1.53$ & $39.12 \pm 0.93$ \\
\hline
\end{tabular}

The study done by Pranoti et al, the maximum transverse diameter of head of humerus was $38.85 \pm 5.09 \mathrm{~mm}$ and $38.18, \pm 4.79 \mathrm{~mm}$ on right and left side respectively where as in this study measurement was $39.01 \pm 1.53 \mathrm{~mm}$ and $39.12 \pm 0.93 \mathrm{~mm}$ on right and left side respectively.
Table 4: Showing comparison of vertical diameter of head of Humerus.

\begin{tabular}{|c|c|c|c|}
\hline Authors & Year & Right & Left \\
\hline Akman et al [11] & 2006 & $41.0 \pm 5.1$ & $40.9 \pm 3.9$ \\
\hline Pranoti et al [10] & 2017 & $42.01 \pm 4.39$ & $40.93 \pm 5.14$ \\
\hline Present study & 2019 & $41.55 \pm 1.12$ & $41.30 \pm 0.90$ \\
\hline
\end{tabular}

The study done by Akman et al, the maximum vertical diameter of head of humerus was 41.0 $\pm 5.1 \mathrm{~mm}$ and $40.9 \pm 3.9 \mathrm{~mm}$ in right and left side respectively where as in the study done by Pranoti et al, the result was $42.01 \pm 4.39 \mathrm{~mm}$ and $40.93 \pm 5.14 \mathrm{~mm}$ in right and left side respectively. These results was similar to our study which was $41.55 \pm 1.12 \mathrm{~mm}$ and $41.30 \pm 0.90 \mathrm{~mm}$ in right and left side respectively.

Table 5: Showing comparision of distance between proximal \& distal edge of Olecranon fossa of Humerus.

\begin{tabular}{|c|c|c|c|}
\hline Authors & Year & Right & Left \\
\hline Akman et al. [11] & 2006 & $24.2 \pm 2.07$ & $23.9 \pm 2.63$ \\
\hline Premchand et al [12] & 2014 & $17.6 \pm 0.16$ & $18.2 \pm 0.15$ \\
\hline Berjina FN et al [13] & 2018 & $17.7 \pm 0.15$ & $18.2 \pm 0.19$ \\
\hline Present study & 2019 & $18.36 \pm 1.08$ & $18.41 \pm 0.77$ \\
\hline
\end{tabular}


In this study, the mean proximal and distal edge of olecranon fossa of humerus was $18.36 \pm 1.08$ $\mathrm{mm}$ and $18.41 \pm 0.77 \mathrm{~mm}$ in right and left side which was very similar to that of study done by Premchand et al and Berjina FN et al.

Table 6: Showing comparision of distance between distal edge of Olecranon fossa \& trochlea.

\begin{tabular}{|c|c|c|c|}
\hline Authors & Year & Right & Left \\
\hline Wright et al. [14] & 2003 & $17.37 \pm 3.36$ & $16.82 \pm 2.20$ \\
\hline Premchand et al [12] & 2014 & $14.00 \pm 1.30$ & $14.40 \pm 0.14$ \\
\hline Present study & 2019 & $15.10 \pm 0.82$ & $14.90 \pm 0.81$ \\
\hline
\end{tabular}

In this study the mean distance between distal edge of olecranon fossa and trochlea was $15.10 \pm 0.82 \mathrm{~mm}$ and $14.90 \pm 0.81 \mathrm{~mm}$ in right and left side which was very close to the study done by Premchand et al.

Table 7: Showing comparision of distance between proximal edge of Olecranon fossa \& distal edge of trochlea.

\begin{tabular}{|c|c|c|c|}
\hline Authors & Year & Right & Left \\
\hline Akman et al. [11] & 2006 & $37.26 \pm 4.71$ & $35.72 \pm 4.30$ \\
\hline Somesh et al. [15] & 2011 & $37.26 \pm 4.71$ & $35.72 \pm 4.30$ \\
\hline Premchand et al [12] & 2014 & $31.60 \pm 2.30$ & $32.70 \pm 2.50$ \\
\hline Present study & 2019 & $33.47 \pm 1.41$ & $33.31 \pm 1.24$ \\
\hline
\end{tabular}

In this study the mean distance between proximal edge of olecranon fossa and distal edge of trochlea was $33.47 \pm 1.41 \mathrm{~mm}$ and $33.31 \pm 1.24$ $\mathrm{mm}$ in right and left humerus respectively which was very close to study done by Premchand et al.

\section{CONCLUSION}

The knowledge of Morphometric segments of Humerus is important to establish the length of humerus, stature, age and sex of individual and it is important for anatomists, forensic experts, archeologists. It is also helpful for orthopaedic surgeons in proximal and distal fracture of humerus and its reconstructive surgery for various implants.

\section{Conflicts of Interests: None}

\section{REFERENCES}

[1]. Nath, S. \& Badkur, P. Reconstruction of stature from long bone lengths. Int. J. Osteoarchaeol., 2002;1:109-14.
[2]. Beddoe, J. On the stature of the older races of England, as estimated from the long bones. J. Anthropol. Inst. Great Brit. Ireland, 1888;17:202-7.

[3]. Petersen, H. C. On the accuracy of estimating living stature from skeletal length in the grave and by linear regression. Int. J. Osteoarchaeol., 2005;15:106-14.

[4]. De Mendonça, M. C. Estimation of height from the length of long bones in a Portuguese adult population. Am. J. Phys. Anthropol., 2000;112(1):39-48.

[5]. Radoinova, D.; Tenekedjiev, K. \& Yordanov, Y. Stature estimation from long bone lengths in Bulgarians. Homo 2002;52(3):221-32.

[6]. Celbis, O. \& Agritmis, H. Estimation of stature and determination of sex from radial and ulnar bone lengths in a Turkish corpse sample. Forensic Sci. Int., 2006;158(2-3):135-9.

[7]. Kate, B. R. \& Majumdar, R. D. Stature estimation from femur and humerus by regression and autometry. Acta Anat., 1976;94:311-20.

[8]. Munoz J.I, Linares Iglesias M, Suarez Penaranda J.M, Mayo M, Miguens X, Rodríguez Calvo M.S, Concheiro L. Stature estimation from radiographically determined long bone length in a Spanish population sample. Forensic Sci Int. 2001;46(2):363- 6.

[9]. Rogers TL. Visual method of determining the sex of skeletal remains using the distal humerus. J Forensic Sci. 1999;44(1):5760.

[10]. Sinha P, Bhutia KL, Tamang BK. Morphometric measurements of segments in dry Humerus. J. Evolution Med. Dent. Sci. 2017;6(67):4819-4822, DOI: 10.14260/Jemds/2017/1045

[11]. V.Akman SD, Karakas PM, Bozkir G. The morphometric measurements of humerus segments. Turkish Journal of Medical Sciences 2006;36:81-5.

[12]. Premchand SA and Manjappa T. Reconstruction of humeral length from measurements of its segments in South Indian population. Int J Sci Res. 2014;3(8):1956-9.

[13]. Naqshi BF, Shah, AB, Gupta S. Olecranon Fossa in Humeri of North Indian Population of Jammu- A Morphometric Study. Journal of Medical Science and Clinical Research. 2018; 6(2): 250-253.

[14]. Wright LE, Vasquez MA. Estimation of the length of incomplete long bones: forensic standards from Guatemala. Am J Phys Anthropol 2003;120(3):23351.

[15. Somesh M. S, Latha V, Prabhu Shilpa K, Mangala M, Ashwin Krishnamurthy B. V, Murlimanju. Morphometric Study of the Humerus Segments in Indian Population. Int. J. Morphol. 2011;29(4):1174-1180.

How to cite this article: Sanjeev Kumar Sinha, Sanjay Kumar, Margaret Roshni Dhan, Vinod kumar. MORPHOMETRIC STUDY OF SEGMENTS OF HUMERUS IN POPULATION OF BIHAR. Int J Anat Res 2020;8(1.1):7217-7220. DOI: 10.16965/ijar.2019.342 